\title{
Development of new C\&W superalloys for high temperature disk applications
}

\author{
Alexandre Devaux ${ }^{1,}$ a , Eric Georges ${ }^{1}$, Philippe Héritier ${ }^{2}$ \\ ${ }^{1}$ Aubert \& Duval, Site des Ancizes BP1, 63770 Les Ancizes Cedex, France \\ ${ }^{2}$ Aubert \& Duval, La Pardieu, 6 rue Condorcet, 63063 Clermont Ferrand Cedex 1, France \\ aalexandre.devaux@eramet-aubertduval.com
}

\begin{abstract}
Key words: superalloys, cast and wrought, phase diagram modeling, disk, strengthening, Microstructural stability
\end{abstract}

\begin{abstract}
The enhancement of efficiency in gas turbine engines requires the development of new superalloys capable of withstanding higher temperatures. The development of novel industrial cast and wrought $(\mathrm{C} \& \mathrm{~W})$ disk alloys with required combination of strength, creep and fatigue resistances at $700^{\circ} \mathrm{C}$ is particularly desired due to the expensive cost of powder metallurgy. In this context, new $\mathrm{C} \& \mathrm{~W}$ disk alloys were recently developed to fulfill these requirements. TMW4 shows higher properties than the current $\mathrm{C} \& \mathrm{~W}$ disk alloy despite an expensive cost due to its high cobalt content, where as 718Plus presents a moderate cost with restricted creep properties at $700^{\circ} \mathrm{C}$ compared to the current U720Li disk alloy. The new nickel base superalloys developed by Aubert \& Duval were therefore designed to offer a better compromise between high temperature properties at $700^{\circ} \mathrm{C}$ and cost. This paper describes the alloy metallurgical features and is especially focused on the alloy design which is extensively based on phase diagram modeling. The study was firstly carried out on small ingots of $6 \mathrm{~kg}$ to optimize the chemistry before forging $200 \mathrm{~kg}$ ingots by industrial processes. The ability to be processed by the conventional cast $\&$ wrought route and the control of the highly expensive elements contents confer to the alloys an attractive cost comparable to that of 718Plus alloy. The high amount of $\gamma^{\prime}$ and the molybdenum-tungsten levels insure higher creep and tensile properties than those obtained with 718Plus.
\end{abstract}

\section{Introduction - Latest developments in $\mathrm{C} \& W$ superalloys for turbine disks}

The latest design of high-efficiency engines has high requirements for the mechanical properties and temperature capability of the key components, especially for the disks of the first stages of the turbine. Alloy development for turbine disk with high properties up to $700^{\circ} \mathrm{C}$ is consequently crucial in order to improve the thermal efficiency in gas turbine engines. 718 alloy which is extensively used for turbine disk is not capable of withstanding temperatures higher than $650^{\circ} \mathrm{C}$ due to the fast coarsening of $\gamma$ ' precipitates above this temperature [1]. U720Li, which is strengthened by $\gamma$ ' phase, has a greater temperature capability and can be processed by the conventional cast \& wrought $(\mathrm{C} \& \mathrm{~W})$ route [2]. However, U720Li is difficult to fabricate by the $\mathrm{C} \& \mathrm{~W}$ route due to its high $\gamma$ ' prime volume content $(45 \%)$ and can be considered as the limit of the $\mathrm{C} \& \mathrm{~W}$ process capability. Because of this and because of its intrinsic raw material content, U720Li is significantly more expensive than alloy 718. TMW alloys were recently developed and apparently present better properties than those of U720Li [3-4]. However, the high cobalt content (table 1) strongly affects the alloy cost which is significantly more expensive than that of other $\mathrm{C} \& \mathrm{~W}$ superalloys (figure 1). 718Plus presents a moderate cost compared to current C\&W superalloys [5-6] due to a reasonable cobalt content and the presence of iron (table 1), but its mechanical properties are significantly lower than those of U720Li and TMW4. Thus, it can be considered that 718Plus and TMW4 do not improve the compromise between cost and mechanical properties currently offered by U720Li. In this context, Aubert \& Duval has focused its research on developing a new C\&W disk superalloy that would improve this compromise. This paper describes the alloy design, extensively based on phase diagram modeling, and the alloy properties. 
Table 1: Chemical composition (wt\%) of various C\&W superalloys for turbine disks $(* \mu \mathrm{g} / \mathrm{g})$.

\begin{tabular}{cccccccccccccc} 
& $\mathrm{Ni}$ & $\mathrm{Fe}$ & $\mathrm{Cr}$ & $\mathrm{Co}$ & $\mathrm{Mo}$ & $\mathrm{W}$ & $\mathrm{Al}$ & $\mathrm{Ti}$ & $\mathrm{Nb}$ & $\mathrm{B}^{*}$ & $\mathrm{Zr}^{*}$ & $\mathrm{C}^{*}$ & $\mathrm{P}^{*}$ \\
\hline U720 & $\mathrm{Bal}$ & - & 16 & 14.5 & 3 & 1.25 & 2.5 & 5 & - & 200 & 300 & 250 & - \\
\hline TMW4 & Bal & - & 15 & 26.2 & 2.8 & 1.15 & 1.9 & 6 & - & 170 & 200 & 200 & - \\
\hline 718 & Bal & 18 & 18 & - & 3 & - & 0.5 & 1 & 5.4 & 40 & - & 250 & 100 \\
\hline 718Plus & Bal & 10 & 18 & 9 & 2.8 & 1 & 1.5 & 0.7 & 5.5 & 40 & - & 250 & 100 \\
\hline
\end{tabular}

\section{Alloy design - Theoretical approach}

Phase diagram modeling was extensively used for alloy design. Thermo-Calc software (S version) was used with two different databases: Ni-data v4 developed by N. Saunders and internal database on nickel alloys developed by N. Dupin. Calculations lead to an original chemistry in the chemical system Ni-Fe-Cr-Co-Mo-W-Al-Ti-Nb-B-Zr-C. This part presents and describes the theoretical features obtained with a new $\gamma / \gamma^{\prime}$ alloy named in this paper Ni30.

Cost of C\&W Ni-based superalloys is mainly governed by $\mathrm{Co}, \mathrm{Ni}$ and $\mathrm{Nb}$ contents which can be accounted for $75 \%$ in alloy cost. As shown in figure $1, \mathrm{Co}, \mathrm{Fe}$ and $\mathrm{Nb}$ contents in Ni30 alloy chemistry were carefully controlled to obtain a cost equal or lower than that of 718Plus. Co and $\mathrm{Nb}$ contents were limited to critical values and Fe was added to consolidate a moderate alloy cost. Niobium was preferred to tantalum for economic reasons. Figure 1 also confirms that U720 and TMW4 alloys are significantly more expensive than 718Plus and Ni30 alloys.

The ability to be easily processed by the conventional $\mathrm{C} \& \mathrm{~W}$ route is absolutely necessary to obtain a competitive alloy in terms of cost. This processing route requires a $\gamma$ ' fraction lower than those of U720Li and TMW4, a control of B, $\mathrm{Zr}$ and $\mathrm{C}$ contents to avoid a low incipient melting temperature and finally low contents of $\mathrm{Ti}, \mathrm{Nb}$ and $\mathrm{Mo}$ which tend to segregate during solidification. Evolution of the liquid phase density during solidification, calculated from liquid composition (Thermo-Calc with Scheil module), may be useful to evaluate the tendency of freckles formation. The workability was evaluated with an internal parameter (Aubert \& Duval experience) based on superalloy chemistry. As shown on figure 1, the workability of the new alloy is expected to be better than those of U720Li and TMW4, which should enable the alloy processing by C\&W route.
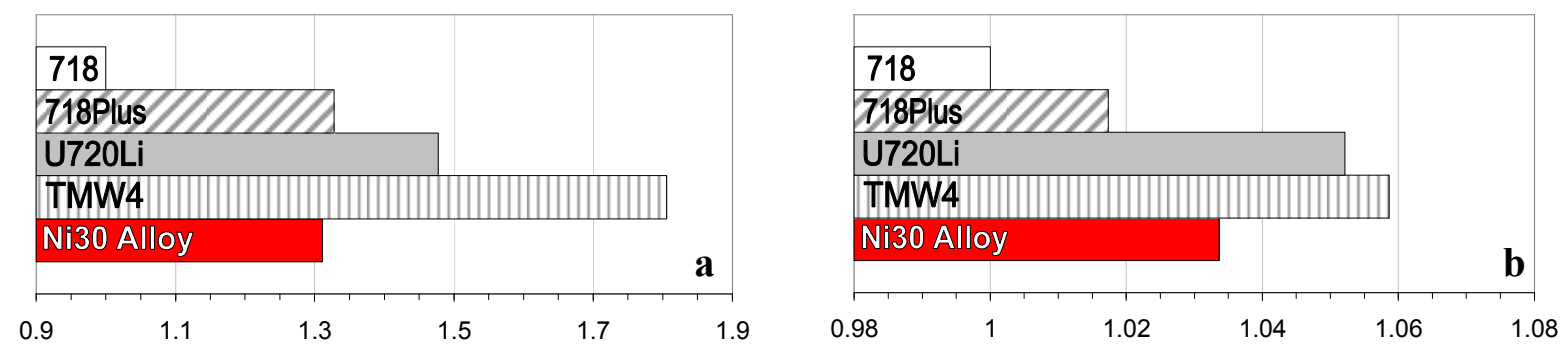

Figure 1: Alloy cost and alloy workability rationalized to 718 ones. (a) Cost (from alloying elements) in April 2008; (b) Workability evaluated with Aubert \& Duval internal parameter.

Microstructural stability is a key parameter to insure high properties for long-term aging in service. New superalloys were therefore strengthened by $\gamma^{\prime}$ phase which is more stable than $\gamma$ ' for temperatures higher than $650^{\circ} \mathrm{C}$. Md parameter at $700^{\circ} \mathrm{C}$, calculated with $\gamma$ matrix chemistry at $700^{\circ} \mathrm{C}$ (determined by Thermo-Calc), was used to evaluate the $\sigma$-proneness of new alloys [7]. Thermo-Calc was also used to estimate the fraction of TCP phases ( $\mu, \sigma$ and P phases) at the equilibrium at $700^{\circ} \mathrm{C}$. According to these two criteria, the new Ni30 alloy show a theoretical microstructural stability at least as good as those of U720Li [8] and 718Plus [9] (figure 2). 

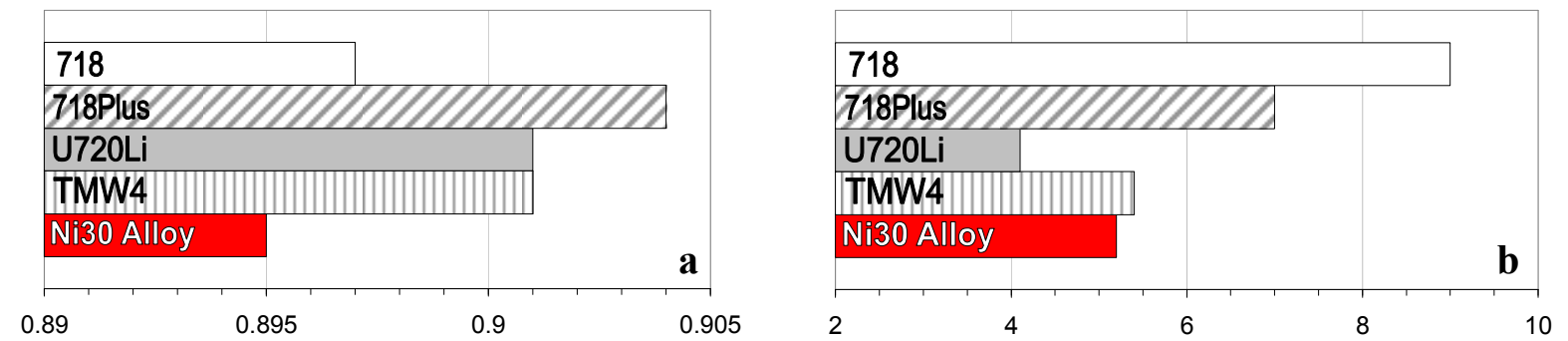

Figure 2: Microstructural stability evaluated with Thermocalc and Ni-based database developed by

N. Dupin. (a) Md Parameter at $700^{\circ} \mathrm{C}$; (b) $\mu$ and $\sigma$ phases molar fraction (\%) at $700^{\circ} \mathrm{C}$.

High creep properties cannot be fulfilled with a low $\gamma^{\prime}$ fraction. The contents of $\gamma^{\prime}$-former elements were consequently adjusted to obtain a $\gamma^{\prime}$ fraction at $700^{\circ} \mathrm{C}$ higher than that of $718 \mathrm{Plus}$ at this temperature. Ni30 alloy presents a $\gamma^{\prime}$ fraction close to $35 \%$ at $700^{\circ} \mathrm{C}$ (figure 3 ). $\mathrm{Nb}$ was selected in new alloys due to its beneficial effect on mechanical properties up to $2.5 \mathrm{wt} \%$ [10]: above this value, this element may be harmful especially for crack propagation. ( $\mathrm{Ti}+\mathrm{Nb}$ )/ $\mathrm{Al}$ ratio is known to be a key factor in superalloy strengthening: $\mathrm{Al}$ atoms are partly substituted by $\mathrm{Nb}$ and $\mathrm{Ti}$ atoms conferring to the $\gamma^{\prime}$ phase a higher strengthening effect. Larger values of $(\mathrm{Ti}+\mathrm{Nb}) / \mathrm{Al}$ ratio lead to a change of the strengthening phase: this is the case for the 718 alloy which is mainly strengthened by $\gamma$ ' phase. This ratio must be carefully controlled in $\gamma / \gamma$ ' superalloys: an excess of $\mathrm{Ti}$ and $\mathrm{Nb}$ for a fixed Al content may lead to the appearance of needle-shaped phases which are deleterious for alloys ductility [11]. It is well established that $\delta$ phase $\mathrm{Ni}_{3} \mathrm{Nb}$ is present in 718Plus (ratio=4.3) [6,9] and that $\eta$ phase $\mathrm{Ni}_{3} \mathrm{Ti}$ may occur in TMW4 (ratio=3) [12]. Thus, $(\mathrm{Ti}+\mathrm{Nb}) / \mathrm{Al}$ ratio was limited in new alloys to more reasonable values in order to avoid the precipitation of these needle-shaped phases (figure 3). $\mathrm{Cr}$ content was adjusted to obtain a sufficient $\mathrm{Cr}$ content in the $\gamma$ matrix at $700^{\circ} \mathrm{C}$.
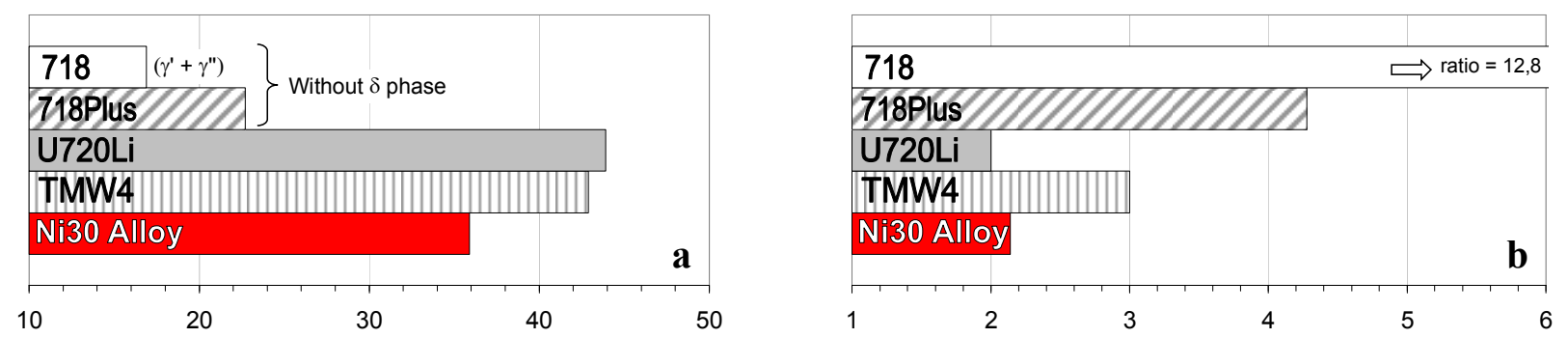

Figure 3: Strengthening by $\gamma^{\prime}$ phase. (a) $\gamma^{\prime}$ molar fraction $(\%)$ at $700^{\circ} \mathrm{C}$ estimated by Thermo-Calc; (b) $(\mathrm{Ti}+\mathrm{Nb}) / \mathrm{Al}$ ratio calculated with weight contents.

Finally, a special attention was paid to solid solution strengthening of $\gamma$ matrix. In addition of Co, Mo and W were the selected elements for this way of strengthening. These elements are known to be beneficial for mechanical properties at high temperatures [13] but strongly affect the alloy density. Mo and $\mathrm{W}$ have been successfully adjusted with Thermo-Calc in order to obtain a higher solid solution strengthening at $700^{\circ} \mathrm{C}$ and a lower density than those of 718 Plus (figure 4). Density was evaluated with the Hull method [14] which provides satisfactory results for superalloys.
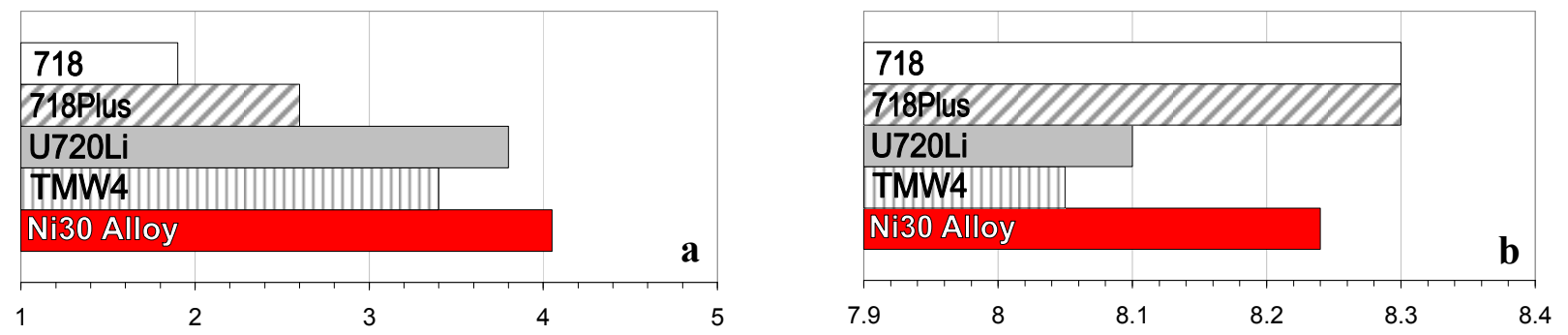

Figure 4: (a) Mo $+\mathrm{W}$ content (at $\%$ ) in $\gamma$ matrix; (b) estimated density in g.cm ${ }^{-3}$. 


\section{Experimental study - Microstructure and features of experimental alloys}

Small ingots of 718Plus (as reference), Ni30, Ni33 and Ni40 alloys were produced through primary vacuum induction melting (VIM) and were hot extruded to $25 \mathrm{~mm}$ bars at a temperature above the $\gamma$ ' solvus. As seen on table 2, Ni33 and Ni40 can be considered as Ni30 derivatives and have the following differences with Ni30 alloy: Ni33 has a higher $\gamma^{\prime}$ amount whereas Ni40 has a higher $(\mathrm{Ti}+\mathrm{Nb}) / \mathrm{Al}$ ratio (table 2$)$.

Table 2: Features of experimental alloys (* calculated with Thermo-Calc)

\begin{tabular}{|c|c|c|c|c|c|c|c|c|c|}
\hline & $\mathrm{Ni}$ & $\begin{array}{c}\text { Fe-Co-Mo-W-Cr } \\
\text { B-Zr-P-C }\end{array}$ & $\mathrm{Al}$ & $\mathrm{Ti}$ & $\mathrm{Nb}$ & $\begin{array}{c}\text { Mo }+W \\
\text { in } \gamma \text { phase* }\end{array}$ & $\begin{array}{c}\gamma^{\prime} \text { solvus } \\
\left({ }^{\circ} \mathrm{C}\right)\end{array}$ & $\mathrm{f}_{\gamma^{*}}$, & $\begin{array}{l}(\mathrm{Ti}+\mathrm{Nb}) / \mathrm{Al} \\
\text { Ratio (wt) }\end{array}$ \\
\hline 718Plus & bal & see table 1 & \multicolumn{3}{|c|}{ see table 1} & 2.6 at $\%$ & 950 & $23 \%$ & 4.4 \\
\hline Ni30 & bal & Reference & \multicolumn{3}{|c|}{ Reference } & $4.0 \mathrm{at}^{\%} \%$ & 1100 & $35 \%$ & 2.3 \\
\hline Ni33 & bal & $\approx \mathrm{Ni} 30$ & $\pi$ & $\pi$ & $\pi$ & $4.1 \mathrm{at} \%$ & 1135 & $39 \%$ & 2.3 \\
\hline $\mathrm{Ni40}$ & bal & $\approx \mathrm{Ni} 30$ & $y$ & $\pi$ & $\pi$ & 3.9 at $\%$ & 1095 & $35 \%$ & 3.0 \\
\hline
\end{tabular}

718Plus samples were heat treated with the standard heat treatment $955^{\circ} \mathrm{C} / 1 \mathrm{~h} /$ air $+790^{\circ} \mathrm{C} / 8 \mathrm{~h} /$ air $+700^{\circ} \mathrm{C} / 8 \mathrm{~h} /$ air. New superalloys Ni30, Ni33 and Ni40 were subsolvus solution heat treated $\left(1050^{\circ} \mathrm{C}\right.$ to $1080^{\circ} \mathrm{C}$ depending on $\gamma^{\prime}$ solvus) and aged at $760^{\circ} \mathrm{C} / 8 \mathrm{~h} / \mathrm{Air}+650^{\circ} \mathrm{C} / 24 \mathrm{~h} /$ Air. As shown on figure 5, similar grain sizes (5 to 6 ASTM) were obtained on experimental alloys. All alloys are $\gamma^{\prime}$ strengthened and two of them (Ni40 and 718Plus) present a needle-shaped phase at grain boundaries. Nodular $\gamma^{\prime}$ phase localized at grain boundaries (primary $\gamma^{\prime}$ ) were not observed due to the temperature of extrusion which was above the $\gamma^{\prime}$ solvus. Subsolvus solution heat treatment for new superalloys Ni30, Ni33 and Ni40 leads consequently to an intragranular bi-modal distribution of $\gamma$ '.
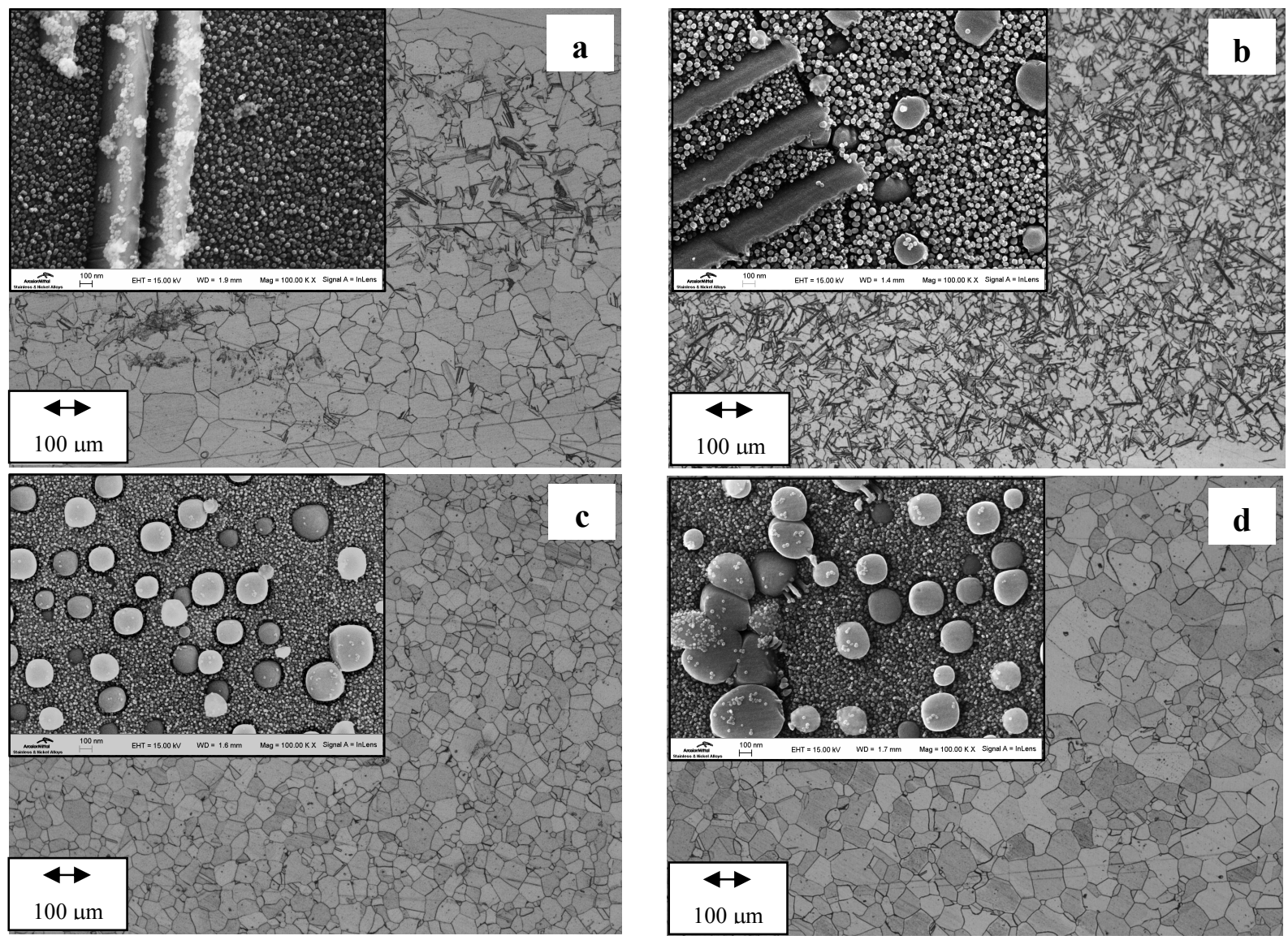

Figure 5: Microstructure of experimental alloys. (a) 718Plus; (b) Ni40; (c) Ni33; (d) Ni30. 


\section{Alloy properties and discussion}

Density measurements reveal that 718 Plus density was equal to $8.3 \mathrm{~g} . \mathrm{cm}^{-3}$ and was higher than that measured on Ni30 and Ni33 alloys: these new alloys have a density close to $8.23 \mathrm{~g} . \mathrm{cm}^{-3}$. Tensile tests performed at $700^{\circ} \mathrm{C}$ show that yield and ultimate tensile strengths of the new alloys are clearly higher than those of 718Plus. Ni40 and Ni33 alloys, which respectively have a higher $(\mathrm{Ti}+\mathrm{Nb}) / \mathrm{Al}$ ratio and a higher $\gamma$ ' fraction compared to Ni30 alloy, show higher tensile strengths. It confirms that these $\gamma^{\prime}$ phase parameters markedly influence tensile strength. Creep tests performed in air at $700^{\circ} \mathrm{C}$ show that secondary creep rate of the new alloys are significantly lower than that obtained on 718Plus. In the same manner, creep rupture life of the new alloys, especially Ni30 and Ni33 ones, are clearly higher than that of 718Plus, with a 5 to 7 times creep rupture life improvement.
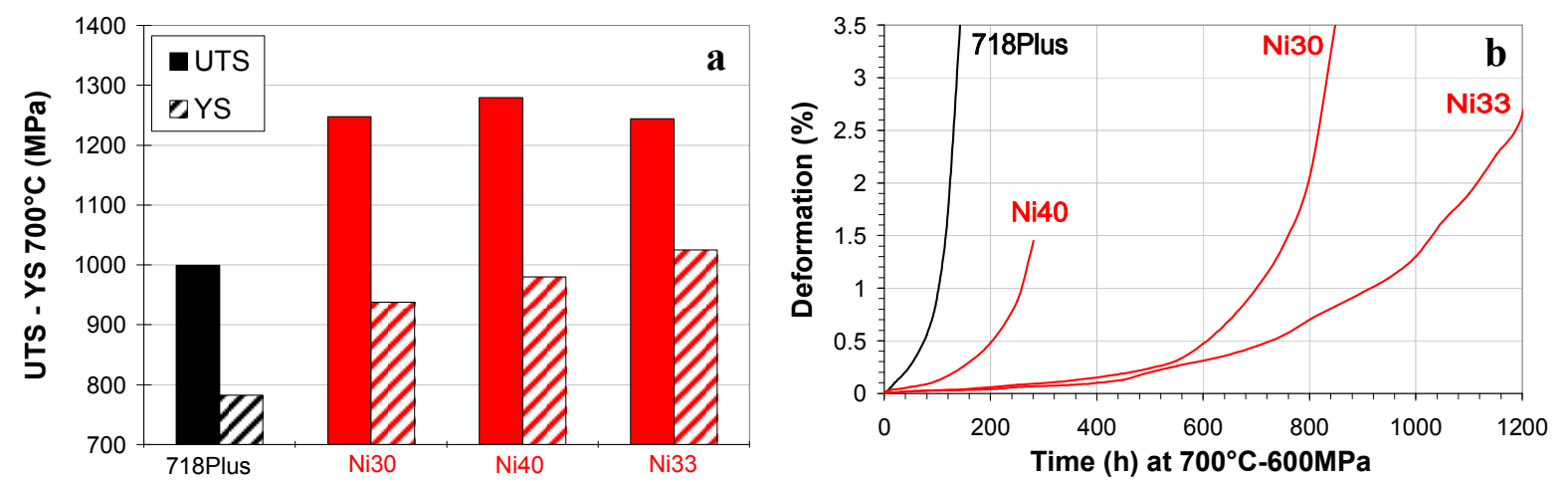

Figure 6: Alloy properties: a) Tensile strength at $700^{\circ} \mathrm{C}$; b) Creep curves at $700^{\circ} \mathrm{C}-600 \mathrm{MPa}$.

Creep ductility of Ni40 alloy was lower than those of other experimental alloys: it strongly suggests that the needle-shaped phase observed in this alloy (figure 5) is responsible for this loss of ductility. As indicated on figure $7, \eta$ phase precipitation is predicted by Thermo-Calc for $(\mathrm{Ti}+\mathrm{Nb}) / \mathrm{Al}$ ratios larger than 2.9. This parameter must be therefore carefully controlled to avoid the precipitation of this deleterious phase. However, the precipitation of $\eta$ phase is not exclusively controlled by $(\mathrm{Ti}+\mathrm{Nb}) / \mathrm{Al}$ ratio: $\mathrm{Co}$ and $\mathrm{Fe}$ may also have an effect by promoting the precipitation of this phase.

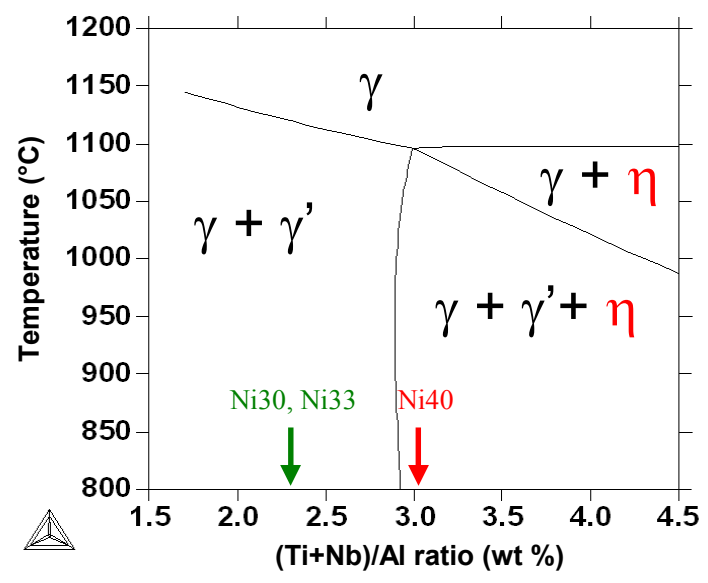

Figure 7: Phase diagram as a function of the $(\mathrm{Ti}+\mathrm{Nb}) / \mathrm{Al}$ ratio (wt $\%)$.

\section{Final evaluation of selected alloys and future prospects}
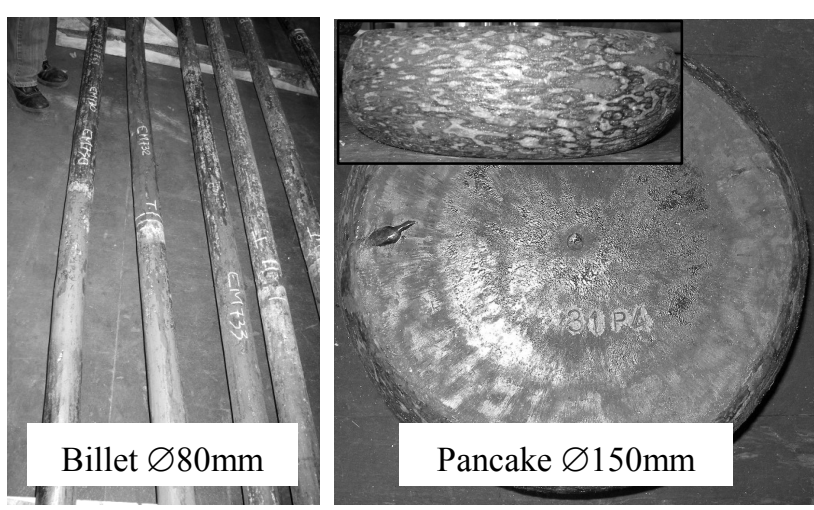

Figure 8: Manufacture from VAR ingots.
Based on these results, Ni30 and Ni33 were selected because of their better properties. VIMVAR (Vacuum Arc Remelted) ingots were produced to confirm the better compromise between cost and properties offered by these new grades. Results confirm that Ni30 and Ni33 alloys can be easily processed by the conventional route (figure 8) and that mechanical properties of new C\&W superalloys are significantly better than those of 718Plus (figure 9) for an equivalent cost. 

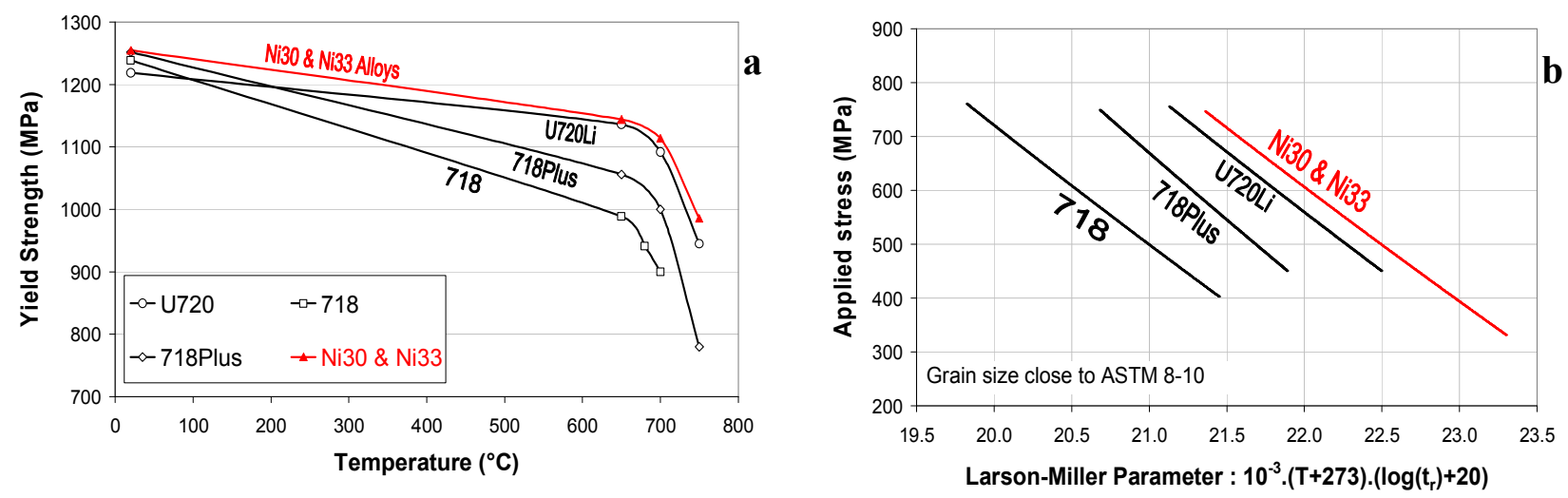

Figure 9: (a) Tensile and (b) creep properties obtained on Ni30 and Ni33 pancakes (average values).

Mechanical properties (figure 9) were obtained on 718Plus and U720Li on forged disks (from industrial heats): grain size was close to 10 ASTM and cooling rate after solution heat treatment was equal to that realized on Ni30 and Ni33 alloys (air cooling on small blanks).

\section{Conclusions}

Aubert \& Duval has developed new C\&W superalloys which present a moderate cost increase compared to 718 alloy: the alloy cost is similar to that of 718Plus and lower than those of other $\gamma / \gamma^{\prime}$ C\&W superalloys (U720Li, TMW4). High $\gamma$ ' fractions (35 to 40\%) associated with a high solid solution strengthening of the matrix explain that tensile and creep properties of these new alloys are clearly higher than those of 718Plus. Mechanical properties of Ni30 and Ni33 are at least similar to those of U720Li. Long term aging is going to be performed to confirm the good theoretical microstructural stability. Based on these first results, it should be possible to extend performance capabilities, in terms of cost and properties, of most current $\mathrm{C} \& \mathrm{~W}$ superalloys for turbine disks.

\section{Acknowledgment}

Authors wish to thank the Imphy Research Center of Arcelor-Mittal for SEM-FEG observations.

\section{References}

[1] J.W. Brooks, P.J. Bridges. Superalloys 1988, Seven-Springs, PA, 33-42.

[2] F.E. Sczerzenie, G.E. Maurer. Superalloys 1980, Seven-Springs, PA, 573-580.

[3] C.Y. Cui, Y.F. Gu, H. Harada, D.H. Ping, A. Sato. Metall Mater Trans., Vol 37A, Nov 2006, 3183-3190.

[4] Y.F. Gu, C. Cui, H. Harada, D.H. Ping, A. Mitsuhashi, K. Kato, T. Kobayashi, J. Fujioka. Superalloys 2008, Seven-Springs, PA, 53-61.

[5] R.L. Kennedy. Superalloys 718, 625, 706 and derivatives, Pittsburgh, PA, 2005, 1-14.

[6] W.-D. Cao, R.L. Kennedy. Superalloys 2004, Seven-Springs, PA, 91-94.

[7] M. Morinaga, N. Yukawa, H. Adachi, H. Ezaki. Superalloys 1984, Seven-Springs, PA, 523532.

[8] P.W. Keefe, S.O. Mancuso, G.E. Maurer. Superalloys 1992, Seven-Springs, PA, 487-496.

[9] W-D. Cao. Superalloys 2008, Seven-Springs, PA, 789-797.

[10] E.C. Guo, F.J. Ma. Superalloys 1980, Seven-Springs, PA, 431-438.

[11] G.K. Bouse. Superalloys 1996, Seven-Springs, PA, 163-172.

[12] C.Y. Cui, Y.F. Gu, D.H. Ping, H. Harada. Metall Mater Trans, Vol 40A, Feb 2009, 282-291.

[13] A.K. Jena, M.C. Chaturvedi. J Mater Sci, vol 19, 1984, 3121-3139.

[14] F.C. Hull, Metal Progress, 11, 1969, 139-140. 